\title{
Effects of management practices on growth rate of pine plantations in Nepal
}

\begin{abstract}
S. P. Dangal ${ }^{1}$ and A. K. Das ${ }^{1}$
With the large scale plantation commenced in the early 1980 s, nearly 370,000 hectares of plantations have been successfully established in Nepal. Pinus patula is one of the dominant species of these plantations aiming to maximize biomass productions in degraded hills. The growth rate of $15 \mathrm{~m}^{3} \mathrm{ha}^{-1} \mathrm{yr}^{-1}$ estimated in 1995 was reduced to $7 \mathrm{~m}^{3} \mathrm{ha}^{-1} \mathrm{yr}^{-1}$ in 2011. As it is an exotic species to Nepal, the effect of management practices on its growth was not clear because of specific ecologic condition which is hindering in developing a management plan with a high confidence. Dendrocronological assessment taking sample cores of 120 trees was conducted in plantations age between 1975 and 1990. The study found that the growth rate decreased after 10 years and the rate was high in the higher density class. The cumulative increment, which was found to be higher in the lower density class, was found to have retarded faster after 15-17 years of age in the higher density class as well as in the informally managed plantations. The study recommends conducting planned thinning from the early age of 8-10 years while the final felling is recommended to be executed at the age of 30-35 years for maximizing its volume. However, a vast area of the current stock, which has already crossed or nearly crossed the rotation age of this species, should be removed in two phases ensuring the establishment of the new crops. They should be clear felled when they reach the age of 45 years.
\end{abstract}

Key words: Management practice, plantation, growth-rate, density, age

L arge-scale plantations in the hilly regions of Nepal were initiated from the early 1980 s (Gilmour et al., 1990). Since then, Nepal could successfully establish more than 370,000 hectare of plantations in the bare hills. Most of the plantations were dominated by pine species (DoF, 2012) including Chir pine (Pinus roxburghii), Blue pine ( $P$. wallichiana) and Patula pine $(P$. patula) that maximize biomass production (Gilmour et al., 1990) as pine was one of the few species which survived and grew well on the areas with very poor soil which were the only sites then available for forest plantations in the hills. Pines withstand grass and weed competition better than some other species (Jackson,1994) as they are morphologically adapted in contrasting disturbance, temperature, precipitation and poor nutrient soil (Knight et al., 1994).

NACRMLP (2006) reports that a total of 23,404 hectares of plantations have been established in Sindhupalchowk and Kavrepalanchowk Districts since the late 1970s, and they were mostly dominated by Pine species (Hunt et al., 2001) among which $40 \%$ is shared by Kavrepalanchowk District. ERI (2011) estimates that P. patula covers almost $75 \%$ of the total Pine plantations. Until late 1970s, the Chaubas Ridge of Kavrepalanchok was a severely degraded overgrazed barren land. With the support of the then Nepal Australia Forestry Project (NAFP), the Department of Forests and the local community jointly started reforestation from the late 1970s. Since then, nearly 400 hectares of degraded land have been reforested mainly with $P$. patula, $P$. roxburghii and $P$. wallichiana (Eijnatten et al., 2001). After the establishment of community saw mills in 1997, intensive thinning using the Thinning Guidelines was commenced in Chaubas. Since then,two to three thinnings, adopting the thinning prescriptions, were carried out in a few community forests in the Chaubas Ridge (Timilsina, 2005).

P. patula, native to Mexico, grows considerably faster than other two indigenous pine species (Jackson, 1994), is likely to be sustainable on most sites where good standard silviculture practices are carried out (Evans, 2000). This three-needled plant, introduced in Nepal back in the 1970s normally grows at the altitude between $1,650 \mathrm{~m}$ and 3,000 $\mathrm{m}$ from the mean sea level (msl) where rainfall ranges from $1000 \mathrm{~mm}$ to

Mewar University, Chittorgarh, Rajasthan, India, Email: shambhudangal@hotmail.com 
$1500 \mathrm{~mm}$. It grows up to $30 \mathrm{~m}$ height and $22 \mathrm{~cm}$ in diameter (dbh). It is fairly tolerant of poor soils and frost-tolerant, and its thin bark is sensitive to fire up to the pole stage (Jackson, 1994).

The maximum annual average growth rate for P. patula recorded in 1995 in Sindhupalchok and Kavrepalanchok Districts was 9.5 ton ha-1 $\mathrm{yr}^{-1}$ (NACFP, 1996) which is equivalent to $15 \mathrm{~m}^{3}$ $\mathrm{ha}^{-1} \mathrm{yr}^{-1}$ for which Ladley (1995) had strongly recommended for timely and appropriate application of silviculture as greater rate of diameter growth is usually obtained in trees after thinning (Dwivedi, 1993). There is an evidence of $27.97 \mathrm{~m}^{3} \mathrm{ha}^{-1} \mathrm{yr}^{-1}$ growth from adoption of such practices (Fox et al., 2007) but due to absence of proper thinning,the growth of these plantations now has been reduced to $7.06 \mathrm{~m}^{3} \mathrm{ha}^{-1} \mathrm{yr}^{-1}$ (ERI, 2011). With the passing of age, density of the stand influence growth rate (Dwivedi, 1993), and similarly,with the advancement of age, the growth relations of the plantation undergo profound changes (Wilde, 1969). Larger the gap, larger will be the mean diameter of edge trees (Berg, 1973), and hence, the selection of stand-level treatment was found to have an important role (BricenoElizondo, 2006).

Defined thinning concepts are neglected within forest management plans, and scientific knowledge about thinning effects on plantation stands is missing (Nenninger et al., 2013). As a result of delayed thinning,an annual loss was estimated to be US\$ $180 \mathrm{ha}^{-1}$ from the plantation in the study area (Hunt et al., 2001). Most of these plantations have crossed 25 years. This time, there was a need for concrete plan for final felling and establishment of second rotation crop. Due to delayed thinning, an extended rotation age of 40-45 years was recommended in 2006 (NACRMLP, 2006). However, thinning and final felling prescriptions were not adopted in most cases as there is a lack of confidence due to limited knowledge on the growth pattern of $P$. patula in
Nepal. Hence, the objective of this study was to assess the effects of management practices, density and age on the radial growth rate of $P$. patula that convince and enable the plantation managers to develop appropriate and adoptable silviculture prescriptions for the management of pine plantations.

\section{Materials and methods}

\section{Study}

The study was conducted in the four community forests viz. Lankuri Rukh Community Forest (CF), Dharapani CF, Bihani CF and Lamrang $\mathrm{CF}$ on the Chaubas Ridge of Kavrepalanchowk District of Central Nepal during May-June 2014. Out of the four CFs, two were thinned as per the respective plans while the remaining two were thinned without any plan i.e. as per the need (Table 1 and Figure 1). All the community forests were situated on the SW- and SE-facing slopes of $20^{\circ}-30^{\circ}$ at the altitude of $1,800-2,000 \mathrm{~m}$ from the mean sea level within a span of $3 \mathrm{~km}$ in the subtropical region. The soil is dominated by clay, red in color, mostly shallow in depth and mixed with small rocks. The precipitation recorded to the nearest hydrological station is $1,923 \mathrm{~mm}$ which falls between June to September (NEA, 2011).

According to the concerned communities,more than 400 ha of forest plantations have been established in the aforementioned CFs since 1970s with an average initial plantation stocking of $1600 \mathrm{ha}^{-1}$.

\section{Sampling design and sample collection}

The study was conducted as a part of "Effect of Growth on Economic Opportunities in Pine Plantations in Nepal". A clear geo-referenced map of the community forests was not available in all the cases which were essential to exactly estimate the area of the study sites and allocation of sample plots. Hence, boundary survey was carried out

Table 1: Details of the study area

\begin{tabular}{clccccc}
\hline \multirow{2}{*}{$\begin{array}{c}\text { Age of plantation } \\
\text { (yrs) }\end{array}$} & \multicolumn{2}{c}{ Formally managed plantations } & \multicolumn{3}{c}{ Informally managed plantations } \\
\cline { 2 - 7 } & $\begin{array}{l}\text { Name of the } \\
\text { CF }\end{array}$ & $\begin{array}{c}\text { stand density } \\
\text { (Tree/ha) }\end{array}$ & $\begin{array}{c}\text { Area } \\
\text { (ha) }\end{array}$ & $\begin{array}{c}\text { Name of } \\
\text { the CF }\end{array}$ & $\begin{array}{c}\text { stand density } \\
\text { (Tree/ha) }\end{array}$ & $\begin{array}{c}\text { Area } \\
\text { (ha) }\end{array}$ \\
\hline $30-35$ & $\begin{array}{l}\text { Lankuri } \\
\text { Rukh }\end{array}$ & 323 & 12.0 & Bihani & 579 & 16.0 \\
$25-30$ & $\begin{array}{l}\text { Dharapani } \\
\text { (Chaubas-7) }\end{array}$ & 570 & 35.0 & Lamrang & 544 & 19.0 \\
\hline
\end{tabular}




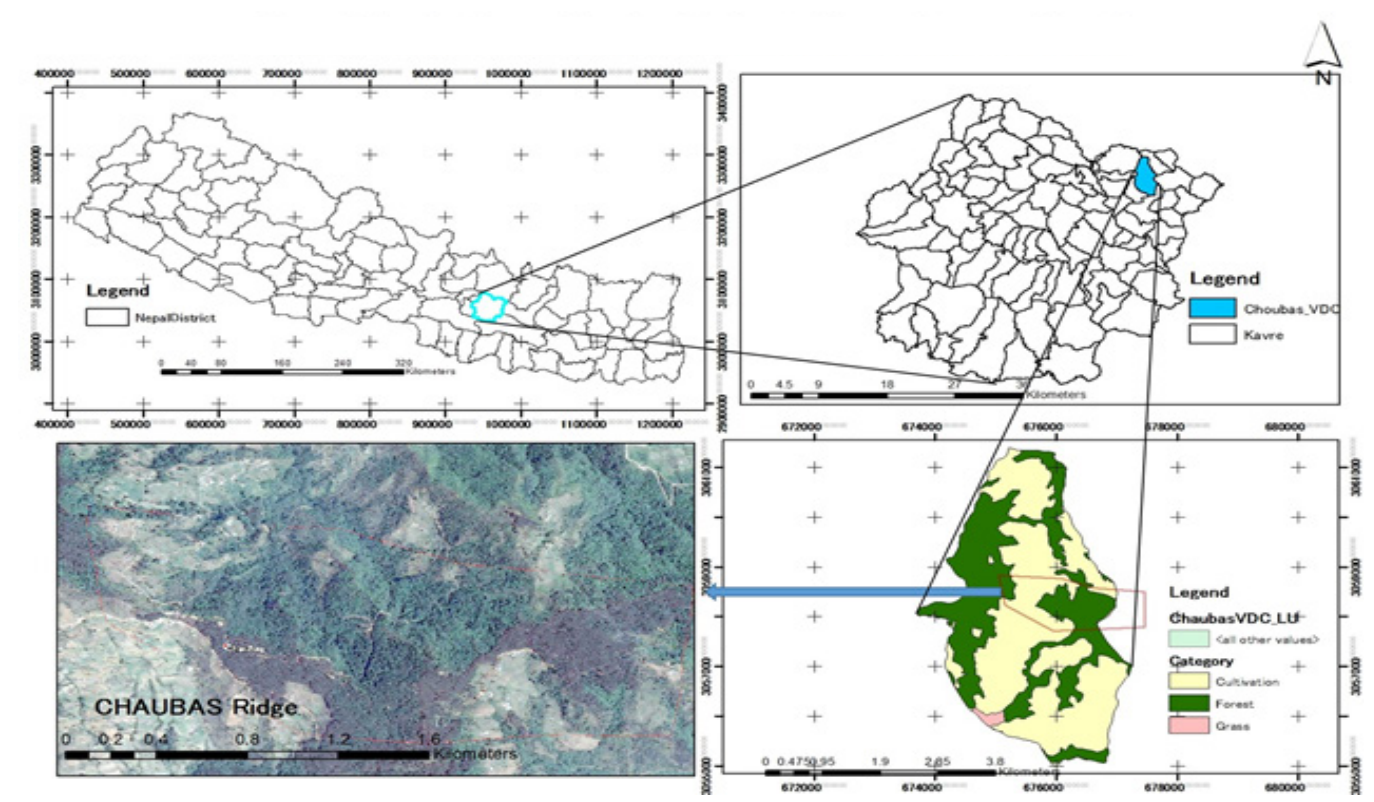

Fig. 1: Map of the study area

using GPS, and the maps were prepared using Arc View Software. A total of 15 sample plots, each with the area of $250 \mathrm{~m}^{2}$, were allocated to each of the four selected CFs; the plots were first located systematically on the maps using computer software and then navigated in the forest with the help of GPS. Thus, altogether 60 plots were established within the four CFS to measure the overall growing stock on the Chaubas Ridge; in each plot, one dominant and one co-dominant trees were identified by measuring their heights with the help of Vertex in order to assess the growth rate.

The measurement method used by Hunt et al. (2001) was adopted throughout the study. From each site, a total of 30 core samples $(0.5 \mathrm{~cm}$ round) were collected with the help of $30 \mathrm{~cm}$ long HAGLOF Increment Borer. The core samples were collected from the most cylindrical section of the stem $20-30 \mathrm{~cm}$ above the ground level (two cores were taken so as to take the average if the tree bole was not cylindrical); the borer was screwed right to the pith, and repeated until the pith could be seen in the core steak. The cores were inserted into straw used for beverage drinking so as to ensure their safety,and were recorded, e.g. L.3.1 (Lankuri Forest, Plot No. 3 and Core No. 1). All the cores were then kept into a $5 \mathrm{~cm}$ diameter and $45 \mathrm{~cm}$ long Polythene Pipe with caps on both ends to protect from seasoning defect, breaking and missing of the cores. Within each sample plot, one dominant and one co-dominant trees were selected, and two $100 \mathrm{~m}^{2}$ nested circular plots were established keeping the dominant and the co-dominant trees at the centres (Figure 2) so as to estimate the stand densities around the mas the trees were growing with different densities. To understand the maximum growth potentiality of the area, a total of 6 biggest trees were selected and their diameters at breast height (dbh), heights and densities along with their core samples were taken and recorded.

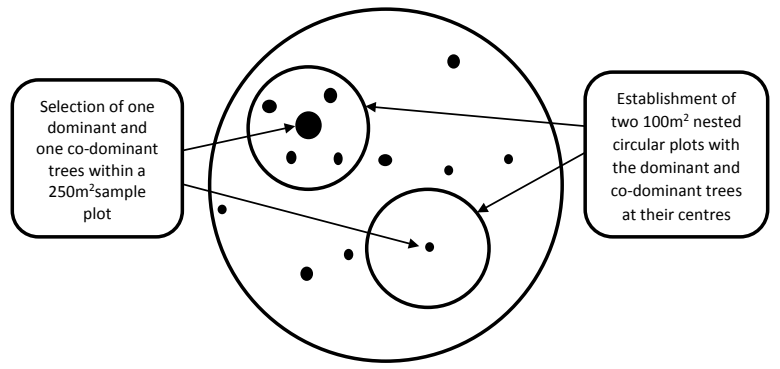

Fig. 2: Selection of one dominant and one codominant trees and establishment of two $100 \mathrm{~m}^{2}$ nested circular plots within a sample plot

For the measurement of core-length, each core was placed in a wooden frame of half circle (half of $0.5 \mathrm{~cm}$ ) perpendicular channel. The core was first well sanded to increase the visibility of rings and then starting from the pith, the length of each section of the core was measured (in $\mathrm{mm}$ ) with the help of Vernier Caliper, and recorded in a format for statistical analysis.

A number of forest managers and planners including the concerned $\mathrm{CF}$ users, the staff of the concerned district forest offices and the Department of Forest, who had past experiences in 
plantation management in Nepal, were consulted as the key informants so as to understand the key issues and challenges for implementation of appropriate management options.

\section{Statistical analysis}

Statistical analysis was performed using Microsoft Excel Program. The analysis in terms of different perspectives of growth response, age, density and management was performed. The stand density was divided into three stocking classes: i)high density class $\left(600-900\right.$ trees ha $\left.{ }^{-1}\right)$, ii) medium density class (300-600 trees ha $\left.{ }^{-1}\right)$ and iii) low density class $\left(<300\right.$ trees $\left.\mathrm{ha}^{-1}\right)$. No sample was found to have over $900 \mathrm{ha}^{-1}$. For simplification, the first ring was considered to be one year old although it was two years old since it takes one year to reach the sapling stage of $20-30 \mathrm{~cm}$ height

\section{Results and discussion}

The analyses of the field data were done for effect on growth of three variables viz. age, density and management regime. The findings of the analyses are as follows:

\section{Effects of age on growth over density}

The aggregated analyses of radial growth with different densities over passing age showed that with the increase in age, the radial growth rate decreased in all the density classes. The reduction in radial growth rate was found to be almost equal until the age of 8-10 years in all the density classes. However, the decreasing rate was noticed higher (600-900 trees $\left.\mathrm{ha}^{-1}\right)$ in the high density class forest plantations after 10 years (Figure 3).

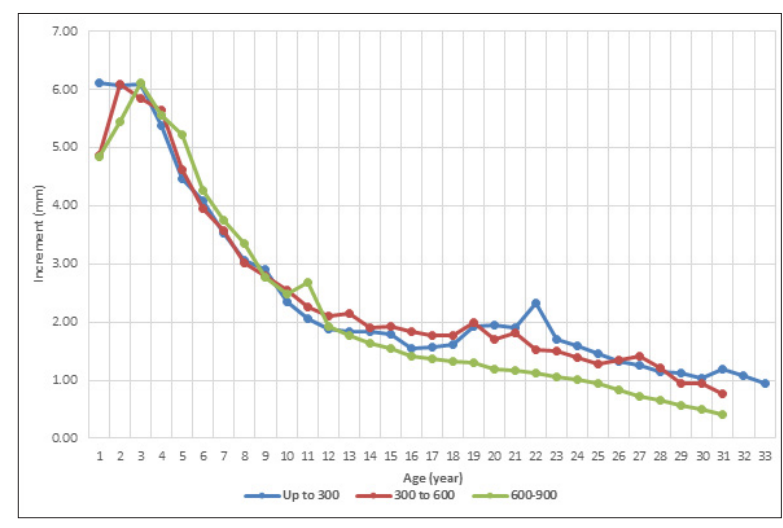

Fig. 3: Variation in annual increment with age

The sharp increase in annual increment in the second year in the two density classes might not be due high density but could be due to the quality of seedling as well as the micro-climate during the plantation. However, there was a continuous fall in increment in the high density class except a small increment after 11 years. The fluctuations after 12 years and 14 years in the low and medium density classes respectively could be due to the effects of two to three thinnings carried out as reported by the key informants as well as on the basis of the available records of the communities. The overall result indicates that the thinning which is carried out in the plantations of the aforementioned species at the age of age of $8-10$ years will increase its growth rate.

\section{Effects of density on growth over age}

The mean annual increments (MAIs) in the three density classes were estimated to be almost similar up to the age of 13-15 years (Figure 4). After this point, the MAI was found to be distinct in the stand density class of $600-900 \mathrm{ha}^{-1}$, but there was no significant difference in the MAI in the stand density class of 300-600 trees $\mathrm{ha}^{-1}$. In the low density class $\left(<300\right.$ trees $\left.\mathrm{ha}^{-1}\right)$, the MAI was found to be higher up to the age of 7 years as compared to the other two density classes, and then there was no difference in its MAI until the age of 16 years. After 16 years, the MAI in the low density class slightly exceeded those in the other two density classes (Figure 4). These differences and similarities, no doubt, affect upon the management practices. It clearly indicates that the density of a stand should be maintained below 600 trees $^{-1} \mathrm{f}^{-1}$ during its age of $15-18$ years to attain a maximum MAI.

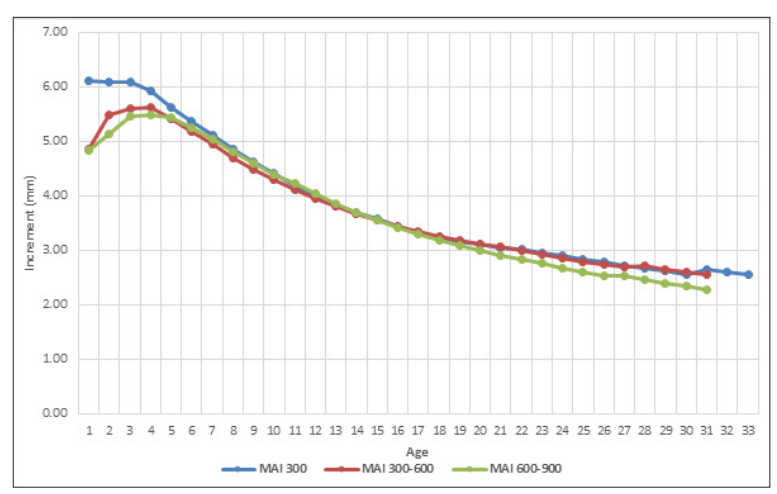

Fig. 4: Variation in mean annual increment (MAI) with density over age

In order to maximize the volume production, analysis of the cumulative increment (MAI) is one of the determining factors for thinning and final felling. The cumulative increment could not be differentiated in the stands until 16 years of 
age, but after 16 years,it decreased more in the high density class than in the other two density classes (Figure 5). This has brought up the similar result as the MAI was found to be almost similar in all the density classes until the age of 16 years. Similarly, the MAI and the cumulative increment in the low and the medium density classes were found to be similar until the age of 30 years after which the MAI,in terms of cumulative increment, in the low density class exceeded those in the other two classes. This indicates that the rotation of $30( \pm 5)$ years could be the best for a stand to attain maximum volume of wood.

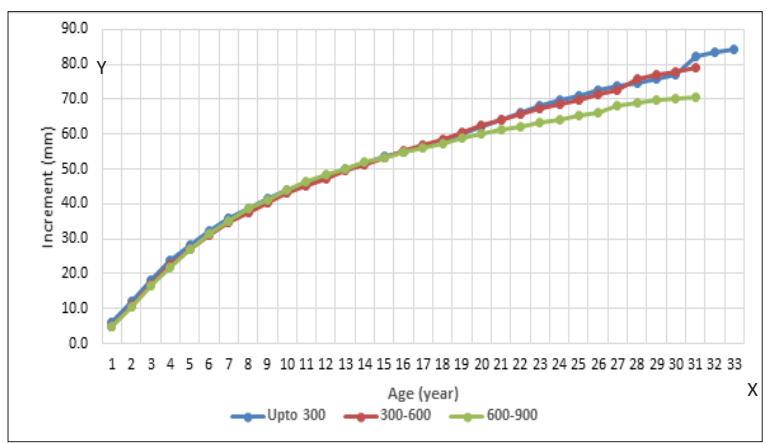

Fig. 5: Variation in cumulative increment with density over age

\section{Growth response in formally and informally managed plantations}

It was notable that the MAIs in the three different density classes were very distinctive in the stands managed under formal and informal management practices (Figure 6 and Figure 7). The reductions in the MAIs between formally and informally managed plantations were found to be almost similar until 12 years. The fluctuations in the MAIs in the density classes could be due to the

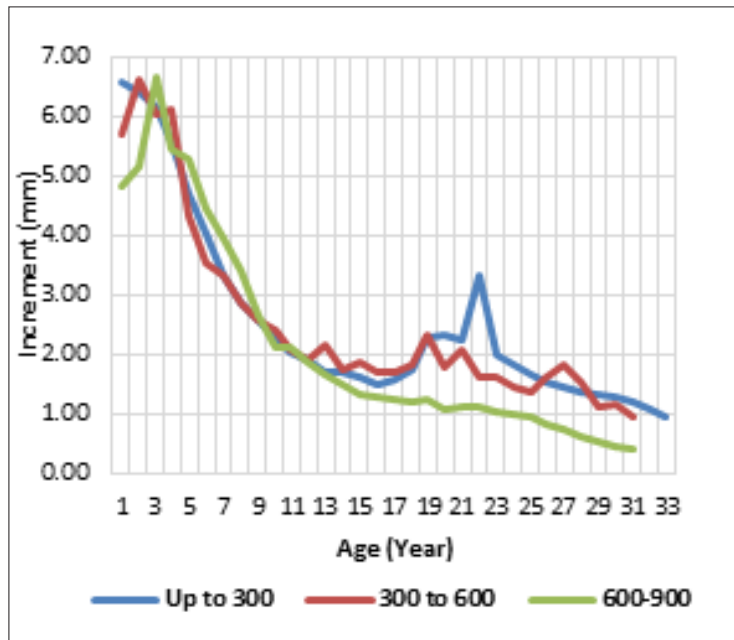

Fig. 6: Variation in annual increment in formal management with age over density site factors in both the cases and also due to the removal of trees in the informally managed plantations. It indicated that there was no effect of density until 12 years of age. After 12 years, the MAI in the informally managed plantations was found to have declined; higher decline in the MAI noticed in the high density class and almost similar decline noticed in the medium and low density classes. Similar pattern was indicated in the high density class in the formally managed plantations, but, fluctuations (sharp increase and decrease)in the MAIs were noticed in the other two density classes. This could be the impact of thinning carried out formally after the age of 12 years until 25 years in the different blocks of the plantations on rotational basis.

The cumulative increment showed a distinct pattern in the formally and informally managed plantations(Figure 8 and Figure 9).

In the formally managed plantations, the cumulative increment was found to be the same up to 17 years of age in all the three density classes, but it was lower in a high density class as compared to those in the other two density classes. Similarly, the cumulative increment rate was higher in the low density class than in the medium density class after 22 years of age. This could be due to the effects of competition for light, and availability of nutrients and ground water as thinnings were conducted from 12 years onwards and the thinning intensity as well as the years of thinning were different due to block management and rotational thinning cycle. This clearly indicated the need for reduction of density below 600 trees ha $^{-1}$ around 15 years. In the plantations under informal management, the

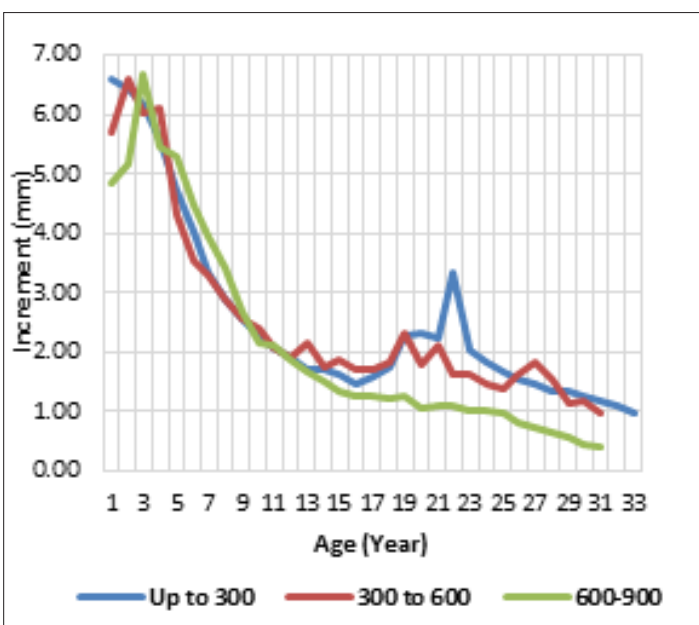

Fig. 7: Variation in annual increment in informal management with age over density 


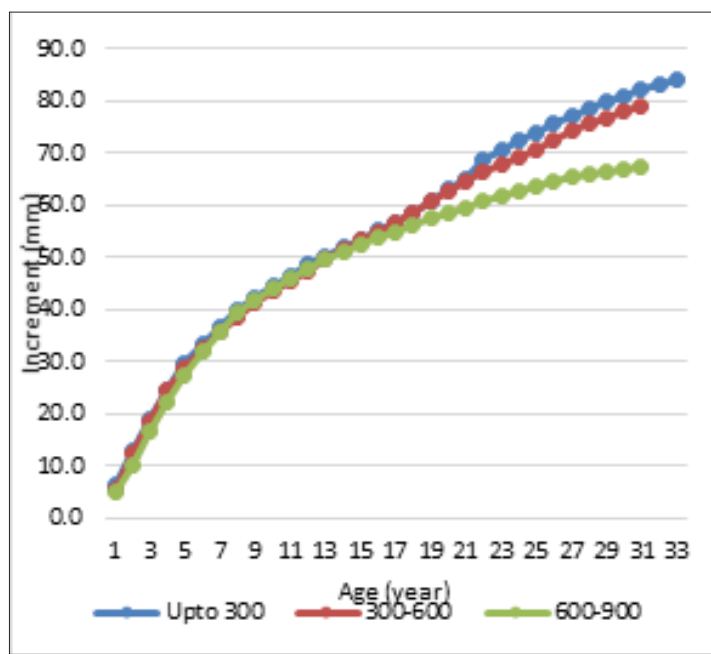

Fig. 8: Variation in cumulative increment in formal management

cumulative increment was the same upto 22 years in all the three density classes, and after then, the increment rate was low in the high density class, but no difference was noticed in the remaining two density classes. It was obvious that although density was similar but the cumulative increments estimated were different between the two managements. This could be due to the planned way of creating space in the formally managed plantations while the haphazard removal of trees in the informally managed ones without looking space, quality of trees and gap. Normally, big trees are found to be removed in the stands managed under informal management leaving the trees with inferior quality which naturally grow slower than the qualitative ones. This becomes opposite in the case of formally managed stands where the dead, diseased, dying, suppressed and inferior trees are removed first leaving the healthier big trees meant for natural regeneration and high return in future. The cumulative increment rate was almost similar in all the three density classes in the informally managed plantation as well as in the low density class in the formally managed plantations. This suggests for reduction of trees in the plantation stands in a planned way from the beginning.

\section{Overall increment and potentiality}

To gauge the maximum growth potentiality in the study sites, measurement of biggest trees were taken. The average density around the biggest trees was estimated to be 310 trees $\mathrm{ha}^{-1}$. The analysis found that there was a big difference between the overall cumulative radial increment $(76 \mathrm{~mm})$ and the cumulative radial increment

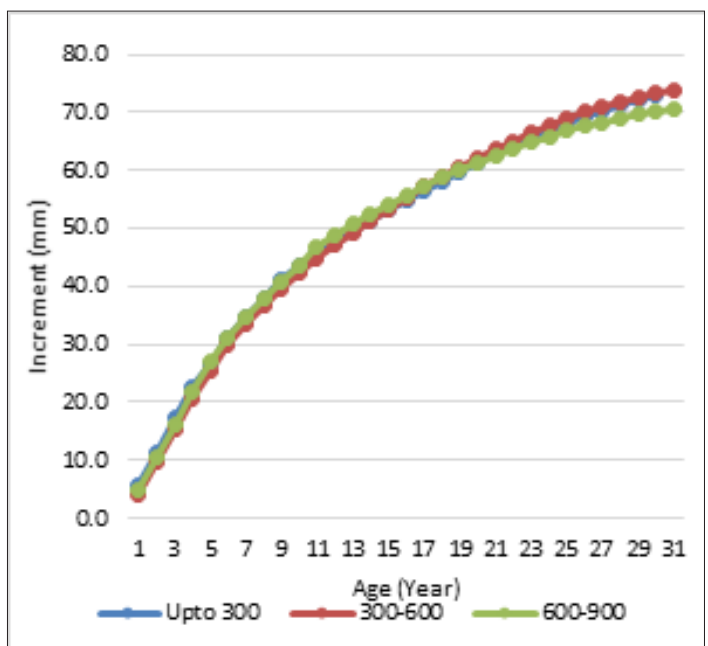

Fig. 9: Variation in cumulative increment in informal management

among the biggest trees $(106 \mathrm{~mm})$ at the age of 31 years (Figure 10 ).

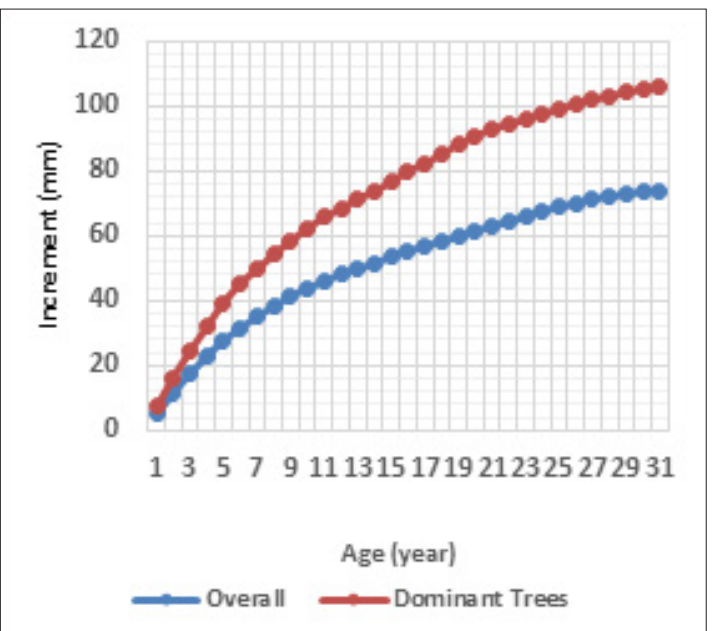

Fig. 10: Variation in cumulative increment between overall and biggest trees

The cumulative increment was found to have retarded after 11 year in overall measurement whereas it was steady among the biggest trees and again retarded after 31 years of age. The high increment in the biggest trees could be due to the availability of sufficient space to grow.

The reduction in the MAI seemed to have similar pattern upto the age of 8 years after which the reduction on the growth in overall measurement was higher than the measurement of biggest trees (Figure 11). However, the gap between the two annual increment curves was found to be narrowed after the age of 23 years, and was quite close after 31 years. As the measurement of a few rings was very difficult after this age, it can be presumed 
that these two curves meet around the age of 3540 years, and will further retard. This implicates that whether there is a reduction in density or not, the growth rates becomes almost stagnant after the age of 35-40 years, and this could be best age for final felling and time to replace by a new crop.

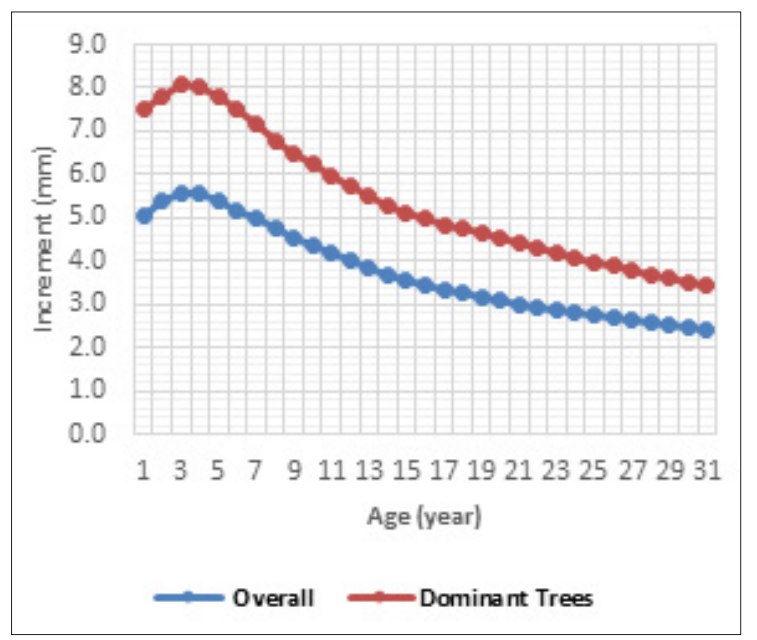

Fig. 11: Variation in average increment between overall and biggest trees

The findings of the analyses showed that the decrease in radial growth with passing age was found to be unavoidable but decreasing the stand density in planned way can reduce the decreasing trend of radial growth rate. It can be concluded that the formal management practice gives better radial growth than the informal management. Similarly, the comparison of disaggregated data of individual trees showed that the radial growth in the early thinning was found to be higher in comparison to the late thinning. Gerelbaatar and Baatarbileg (2011) have concluded that the radial growth of Scotch pine do not vary by site but more intensive annual increment and radial growth improve in the plantation of $8-15$ years of age. The amount of annual height increment and radial growth improve regularly up to 9-11 years of age, and then the intensity of annual increment declines due to competition for light and nutrients. The result suggests for reduction in a stand density after 9-11 years of plantation that avoid restriction of growing conditions.

Based on the input and output ratio, the late thinnings have limited impact on radial increment. Because of low intensity thinning, the increase in radial growth rate is found to be effective for the period of only 4-5 years after thinning which again remains similar to the pre-thinning conditions. This implicate that planned thinning is essential from the early age before canopy closes as recommended by Briceno-Elizondo (2006), and if the intensity of thinning is low, the thinning cycle should be shorter.

The present issue ahead is how to manage the current plantations of the study sites and other similar plantations. The thinning guidelines developed by NACRMLP (2006), does not explicit the application of thinning regime when the current age is between 25 and 35 years, but reference to nearestage (20-25 years) recommends that stocking at current stage should be 150 trees ha $^{-1}$ for 31-35 year-old plantations and 220 trees $\mathrm{ha}^{-1}$ for 26-30 year-old plantations maintaining rotation periods of 40 and 45 years respectively. The guideline suggests one additional thinning for 26-30 year old plantations at the age of 40 years. Similar recommendations were made by Dangal and Arrentz (2002). They recommended extended rotation period up to 55 years for the plantations where thinnings and final felling were delayed. They suggested retaining 150, 200 and 300 trees ha $^{-1}$ to follow the rotation periods of 45, 50 and 55 years respectively. Hunt et al.(2001) suggested a rotation age of maximum of 45 years, and thin to 150 tree ha ${ }^{-1}$ when they reach the age of 30-35 years. These all are extended rotation age than the actual recommended rotation age in normal forest management situation. A rotation age of 35 years with 4 high intensity thinning has been practiced in Kenya (FD/KEFRI, 1997) whereas in the USA, $P$. radiata stands are managed up to three regimes depending on potential productivity. This involves two thinnings to give a final crop stocking of 200 stems ha $^{-1}$ and clear felling occurs at the age 30 year (Berg, 1973).

In native habitat, $P$. patula grows up to $30 \mathrm{~m}$ height and $22 \mathrm{~cm}$ diameter (Jackson, 1994), but this study found a maximum of $64 \mathrm{~cm}$ diameter with a similar height of $30 \mathrm{~m}$. This indicates that there is a competition for light due to which trees gain height but not diameter. Looking at the financial aspect, the MFC (2007) estimates an income of 9,250 US\$ ha ${ }^{-1}$ from a plantation stock of 1000 trees $\mathrm{ha}^{-1}$ on a normal site quality at the age of 10 years and with two thinnings at the age of 15 and 22 years and the final felling at the age of 35 years. In the study sites, there was no specific plan for the final felling of the plantations. The case of Mississippi suggests that the plantations in the study area has now reached the final harvesting stage as most of the plantations have already 
crossed thinning age leading to an annual loss of almost US\$ $180 \mathrm{ha}^{-1}$ (Hunt et al., 2001). To reduce the further loss from the delayed thinning and final felling,there is an urgent need to develop proper plan to manage these plantations. Despite after 25 years, a negligible growth is estimated by the study, it would not be wise to conduct final felling at this stage as there is a need for proper replacement of this crop by a new one. Hence, in spite of a negligible increment, it is wise to maintain rotation period of 40-45 years on the basis of the existing density. One or two thinnings would be required to retain 100-150 stems ha-1 for final felling based on the existing stock which can be removed after new crop has been established

\section{Conclusion}

Based on the findings of the analysis and discussions, the study draws a number of conclusions. With passing age, the growth rate decreases regardless of density until 10 years of age, and the rate of declination increases in high density class. There is a significant effect of density on the growth rate after 10 years. The increasing retardation on MAI and Cumulative Increment in the medium density class (600-900 trees $\mathrm{ha}^{-1}$ ) than in the other two density classes after 16 years of age demands for retaining density less than 600 trees ha ${ }^{-1}$ at the age of 15 17 years. The overall increment in the formally managed plantations is higher than those under informal management. However, the effect of formal management is slightly higher than that of informal management which is highly distinctive only after 15-17 years of age. The study further concludes that both the age and density have significant effects on growth, and so, formal management practice is necessary to maintain required density in the plantations.

The following recommendations could be useful for plantation managers including government, private sector, academia and the CF users of Nepal:

- To reduce the cost of plantation and initial competitions among the trees for light and nutrients and in such areas where early thinning cannot be ensured, planting stocking of around 1000-1100 stems ha-1 will be sufficient. Plantation spacing could be $3.25 \mathrm{~m}$ $\times 3.25 \mathrm{~m}$ or $3 \mathrm{~m} \times 3 \mathrm{~m}$. In such case, thinning can be carried out at the age of $12-15$ years.
- Late thinning has less effect on radial increment. The reduction of plantation stock in systematic and planned way from earlier stage will be highly beneficial. For new plantations, a 30-year rotation period is generally recommended to receive bigsize timber; however, for pole size timber, a rotation period of 22-25 years would be ideal. Four thinnings are recommended for bigsize timber production. The regime proposed for new plantations with plantation stock of 1,600/ha is presented in Table 2 below:

Table 2: Proposed thinning regimes for new plantations

\begin{tabular}{lccccc}
\hline Age (years) & $\mathbf{8 - 1 0}$ & $\mathbf{1 3 - 1 5}$ & $\mathbf{1 9 - 2 1}$ & $\mathbf{2 6 - 2 9}$ & $\mathbf{3 0 - 3 5}$ \\
\hline $\begin{array}{l}\text { Stand density } \\
\text { to be retained } \\
\left(\mathrm{ha}^{-1}\right)\end{array}$ & $\begin{array}{c}800- \\
1000\end{array}$ & $\begin{array}{c}500- \\
700\end{array}$ & $\begin{array}{c}200- \\
400\end{array}$ & $\begin{array}{c}100- \\
150\end{array}$ & 0 \\
\hline
\end{tabular}

- For the existing plantations of the study sites and similar conditions, it is less likely that thinning will significantly increase the radial growth. But, due to slope terrain, the final felling without establishing new crop is not recommendable. So, phase-wise reduction and final felling is ideal. The current stocking needs to be maintained at 100-150 trees $\mathrm{ha}^{-1}$ for next 5-10 years so as to allow natural regeneration or plantation to be established. Once new crops are established, the remaining trees can be removed.

\section{References}

Berg, P. 1973. Silviculture of Pinus radiata stand edge trees at wood hills forest. NZ Journal of Forestry 18: 115-123.

Briceno-Elizondo, E. 2006. Stand Level Analysis on the Effects of Management and Climate Change on the Growth and Timber Yield with Implication on Carbon Stocks in Boreal Forest Ecosystem: A Model Based Approaches. The Finnish Society of Forests Science; Finnish Forest Research Institute; Faculty of Agriculture and Forestry, University of Helsinki; Faculty of Forestry, University of Joensuu. Dissertation Forstales 24: 17957389 .

Dangal, S. and Arentz, F. 2002. Management of Pine Plantation in the Nepal-Australia Community Resources Management 
Project. Nepal-Australia Community Resources Management Project, Kathmandu, Nepal.

DoF. 2012. Community Forest Data Base. Community Forestry Division, Department of Forest, Ministry of Forest and Soil Conservation, Kathmandu, Nepal.

Dwivedi, A. 1993. A Text Book of Silviculture. Dehra Dun, India.

Eijnatten, J. V., Acharya, H., and Shrestha, S. 2001. Organizational Change in Four FUGs: Operating the Chauba-Bhumlu Community Sawmill. Nepal Australia Community Resources Management Project, Kathmandu, Nepal.

ERI. 2011. A Feasibility Study Report to Establish Pine Wood Treatment Plant in the Middle Hills of Nepal. Environmental Resources Institute Pvt. Ltd. and Micro Enterprise Development Programme of UNDP, Kathmandu, Nepal.

Evans, J. 2000. Sustainability of productivity in successive rotation. In Timber Plantation Development (ed) Manila, Philippines, 321344.

FD/KEFRI. (1997). Silviculture Regimes for Plantation Forest in Kenya. Forest Department Karura, Kenya. Retrieved from: http://www.fernis.net/system/files/current silviculture_regime.pdf. Accessed on: $2^{\text {nd }}$ May, 2013.

Fox, T. R., Jokela, E. J. and Allen, H. L. 2007. The development of pine plantation silviculture in the Southern United States. Journal of Forestry 105: 337-347.

Gerelbaatar, S. and Baatarbileg, N. 2011. Growth of Scotch pine (Pinus sylvestris L.) plantation in Northern Mongolia. Journal of Agriculture and Technology (B1): 1205-1210.

Gilmour, D., King, G., Applegate, G. and Mohns, B. 1990. Silviculture of plantation forest in central Nepal to maximize community benefits. Forest Ecology and Management 32: 173-186.

Hunt, S., Dangal, S. and Shrestha, S. 2001. The Impact of Stocking on the Growth of Pine Plantations in the Mid Hills of Kabhrepalanchok and Sindhupalchok.
Nepal Australia Community Resource Management Project, Kathmandu, Nepal.

Jackson, J. 1994. Manual of Afforestation in Nepal. Forest Research and Survey Centre, Ministry of Forests and Soil Conservation, Kathmandu, Nepal.

Knight, D. H., Vose, J. M., Baldwid, V. C., Ewel, K. C. and Grodzinska, K. 1994. Contrasting pattern in pine forest ecosystems. Ecological Bulletins 43: 9-19.

Ladley, J. C. 1995. Opportunities for Income Generation from Pine Plantations in Kavrepalanchowk and Sindhupalchowk. Nepal Australia Community Forestry Project, Kathmandu, Nepal.

MFC. 2007. How Much is Your Plantation Worth? Mississippi Forestry Commission, Jackson, Mississippi.

NACFP. 1996. A Feasibility Study for Timber Processing by Forest User Groups in the Middle Hills of Nepal. Nepal Australia Community Forestry Project, Kathmandu, Nepal.

NACRMLP. 2006. Thinning Guidelines for Pinus patula and Pinus roxburghii Plantations in Nepal. Nepal Australia Community Resource Management and Livelihood Project, Kathmandu, Nepal.

NEA. 2011. Initial Environmental Examination. Nepal Electricity Transmission Expansion and Supply Project, Kathmandu, Nepal.

Nenninger, A., Kateb, H. E., Fetene, M. and Mosandl, R. 2013. Functional Ecology and Sustainable Management of the Munessa Forest, Ethiopia. Retrieved from http:/www. soils.uni-hannove.de/foreschung/monessa. com. Accessed on $1^{\text {st }}$ May, 2013

Timilsina, N. 2005. Supporting Livelihood through Employment: The Chaubas Bhumlu Community Sawmill, Nepal. ITTO, Forest Trends, RECOFTC, Right and Resource Initiative.

Wilde, S. A. 1969. Pine Internodes as Indicators of Non-Determinable Environmental Influences. Wisconsin Academy of Science, Arts and Letters, Madison, USA. 